\title{
High-Throughput Chlorophyll and Carotenoid Profiling Reveals Positive Associations with Sugar and Apocarotenoid Volatile Content in Fruits of Tomato Varieties in Modern and Wild Accessions
}

\author{
Yusuke Aono ${ }^{1}$, Yonathan Asikin ${ }^{2}$ (D), Ning Wang ${ }^{3,4}$, Denise Tieman ${ }^{5}$, Harry Klee ${ }^{5}$ and Miyako Kusano ${ }^{3,4,6, *(D)}$ \\ 1 Degree Programs in Life and Earth Sciences, University of Tsukuba, Tsukuba 305-8572, Ibaraki, Japan; \\ s2030229@s.tsukuba.ac.jp \\ 2 Department of Bioscience and Biotechnology, Faculty of Agriculture, University of the Ryukyus, Nishihara \\ 903-0213, Okinawa, Japan; y-asikin@agr.u-ryukyu.ac.jp \\ 3 Faculty of Life and Environmental Science, University of Tsukuba, Tsukuba 305-8572, Ibaraki, Japan; \\ wang.ning.fu@u.tsukuba.ac.jp \\ 4 Tsukuba-Plant Innovation Research Center, University of Tsukuba, Tsukuba 305-8572, Ibaraki, Japan \\ 5 Department of Horticultural Sciences, University of Florida, Gainesville, FL 32611, USA; \\ dtieman@ufl.edu (D.T.); hjklee@ufl.edu (H.K.) \\ 6 RIKEN Center for Sustainable Resource Science, Yokohama 230-0045, Kanagawa, Japan \\ * Correspondence: kusano.miyako.fp@u.tsukuba.ac.jp
}

\section{check for} updates

Citation: Aono, Y.; Asikin, Y.; Wang, N.; Tieman, D.; Klee, H.; Kusano, M. High-Throughput Chlorophyll and Carotenoid Profiling Reveals Positive Associations with Sugar and Apocarotenoid Volatile Content in Fruits of Tomato Varieties in Modern and Wild Accessions. Metabolites 2021, 11, 398. https://doi.org/10.3390/ metabo11060398

Academic Editor: Peter Meikle

Received: 13 May 2021

Accepted: 16 June 2021

Published: 18 June 2021

Publisher's Note: MDPI stays neutral with regard to jurisdictional claims in published maps and institutional affiliations.

Copyright: (c) 2021 by the authors. Licensee MDPI, Basel, Switzerland. This article is an open access article distributed under the terms and conditions of the Creative Commons Attribution (CC BY) license (https:// creativecommons.org/licenses/by/ $4.0 /)$.

\begin{abstract}
Flavor and nutritional quality has been negatively impacted during the course of domestication and improvement of the cultivated tomato (Solanum lycopersicum). Recent emphasis on consumers has emphasized breeding strategies that focus on flavor-associated chemicals, including sugars, acids, and aroma compounds. Carotenoids indirectly affect flavor as precursors of aroma compounds, while chlorophylls contribute to sugar production through photosynthesis. However, the relationships between these pigments and flavor content are still unclear. In this study, we developed a simple and high-throughput method to quantify chlorophylls and carotenoids. This method was applied to over one hundred tomato varieties, including S. lycopersicum and its wild relatives (S. l. var. cerasiforme and S. pimpinellifolium), for quantification of these pigments in fruits. The results obtained by integrating data of the pigments, soluble solids, sugars, and aroma compounds indicate that (i) chlorophyll-abundant varieties have relatively higher sugar accumulations and (ii) prolycopene is associated with an abundance of linear carotenoid-derived aroma compounds in one of the orange-fruited varieties, "Dixie Golden Giant". Our results suggest the importance of these pigments not only as components of fruit color but also as factors influencing flavor traits, such as sugars and aroma.
\end{abstract}

Keywords: tomato; fruit pigment; flavor; apocarotenoid; sugar accumulation; aroma compounds; carotenoid; lycopene; chlorophyll

\section{Introduction}

Tomato is one of the most important vegetables worldwide. Recent breeding strategies have focused not only producer-favorable traits such as high yield, long shelf life, and disease resistance, but also on flavor [1]. The major flavors of tomato are the result of interactions between taste and aroma [2]. In tomato fruits, sugars (mainly glucose and fructose) and acids (mainly citrate, malate, and ascorbate) are perceived by taste receptors, while various volatile organic compounds (VOCs) are perceived by olfactory receptors [3]. To improve fruit flavors, many genetic approaches have been conducted [4-6]. Wild relatives that can be crossed with cultivated tomatoes (S. lycopersicum), such as S. $l$. var. cerasiforme and S. pimpinellifolium, are important genetic resources that have been exploited to provide insights into the synthesis of flavor-associated chemicals $[5,6]$. 
Fruit color is also an important factor in determining commercial value [7]. Among cultivated tomatoes (S. lycopersicum), several varieties show various colors of mature fruits, including green, orange, pink, brown, yellow, and red [8]. Fruit color in tomato is produced by several pigments. The pericarp contains carotenoids and chlorophylls, while the peel primarily contains flavonoids [9]. In parallel with the change from green to red during ripening, various events, such as the accumulation of carotenoids, degradation of chlorophylls, starch decomposition into monosaccharides, reduction of organic acids, and fruit softening, occur in a coordinated manner $[10,11]$. The ripening process also causes changes in VOC composition [12]. VOCs at the mature red stage provide a commercially valuable aroma $[13,14]$.

Prior research indicates that some tomato fruit color mutations can affect the composition of nutritional and flavor compounds; therefore, chlorophylls and carotenoids exhibit the potential to improve flavors in tomato fruits [15]. Even though photosynthetic capacity in tomato fruits is limited compared to leaves, chlorophyll content can be associated with sugar accumulation in fruits $[16,17]$. Carotenoids are known to be important for human health benefit to decrease the risk of disease [18]. Furthermore, carotenoids are precursors of apocarotenoid (AC)-VOCs, providing fruity/floral aroma notes, although carotenoids themselves are tasteless [19]. AC-VOCs can enhance the perception of sweetness [20] and contribute positively to consumer preferences [21]. Several genes regulating fruit color and pigment content have been identified [22]. To date, the relationships between these pigments and flavors are not fully understood.

High-performance liquid chromatography (HPLC) combined with a photodiode array detector (PDA) is widely used for the identification and quantification of carotenoids [23-26]. However, these methods generally require $20 \mathrm{~min}$ or more per sample. This time commitment per sample is a burden on the researcher; therefore, a higher-throughput method is highly desirable for analysis of large sample sets. For quantification of carotenoids and chlorophylls, simple methods using a spectrophotometer are well established [27-29]. Despite the acceptance of these methods, optimization is still needed to achieve highthroughput measurements that will enable the analysis of large sample populations.

In this study, we developed a simple and rapid method for the quantification of non-polar pigments. Applying this method, we quantified these pigments in mature fruits of over one hundred varieties of tomato. Combining this pigment analysis with flavor analysis suggested that the sugar content can be linked to the accumulation of chlorophylls in tomato fruit. Additionally, one tomato variety in this analysis showed a unique carotenoid metabolite composition, including increased AC-VOCs.

\section{Results}

2.1. Method Development for High-Throughput Quantification of Carotenoids, Lycopene, and Chlorophylls in Tomato Fruits

To provide new insights into the relationship between nonpolar pigments and flavorrelated compounds, we developed the simple and high-throughput method for pigment quantification in tomato fruits (Figure 1). When comparing classical methods using a spectrophotometer with a spectrophotometer cell, the developed method using 96-well plates and a microplate reader exhibited three distinct advantages. First, sample measurements require only $300 \mu \mathrm{L}$, equivalent to only $0.75 \mathrm{mg}$ of dry sample weight. Second, the use of a multimode microplate reader to measure five wavelengths allowed for the quantification of carotenoids, lycopene, and chlorophylls a and b simultaneously. The developed method can quantify the total content of carotenoids and lycopene content at the wavelengths of 470 and $506 \mathrm{~nm}$, respectively. The limits of detection of each analyte (chlorophyll a, chlorophyll $\mathrm{b}$, total carotenoids, and lycopene) were $0.029,0.12,0.05$, and $0.071 \mu \mathrm{g} / \mathrm{mL}$, respectively (Figure S1). The sensitivity for carotenoid and lycopene quantification was comparable to previous HPLC analysis [30]. The accuracy of the method was validated by comparing the results of the pigment content in "Micro-Tom" fruits obtained from HPLC-PDA analysis (Figure S2). The results of the pigment content analyzed by the microplate reader and by HPLC-PDA showed a positive correlation with a high correlation coefficient $\left(R^{2}>0.8\right)$. 
Third, the acquisition time is very short; each sample is analyzed in approximately $10 \mathrm{~s}$. The method can analyze 24 samples per $2.5 \mathrm{~min}$ automatically as one batch. These results suggest that the developed method allows the quantification of hundreds of samples much faster than the use of HPLC-PDA methods with equivalent accuracy.

Mature tomato fruits from 157 varieties

(S. lycopersicum, S. I. ver. cerasiforme, and S. pimpinellifolium)

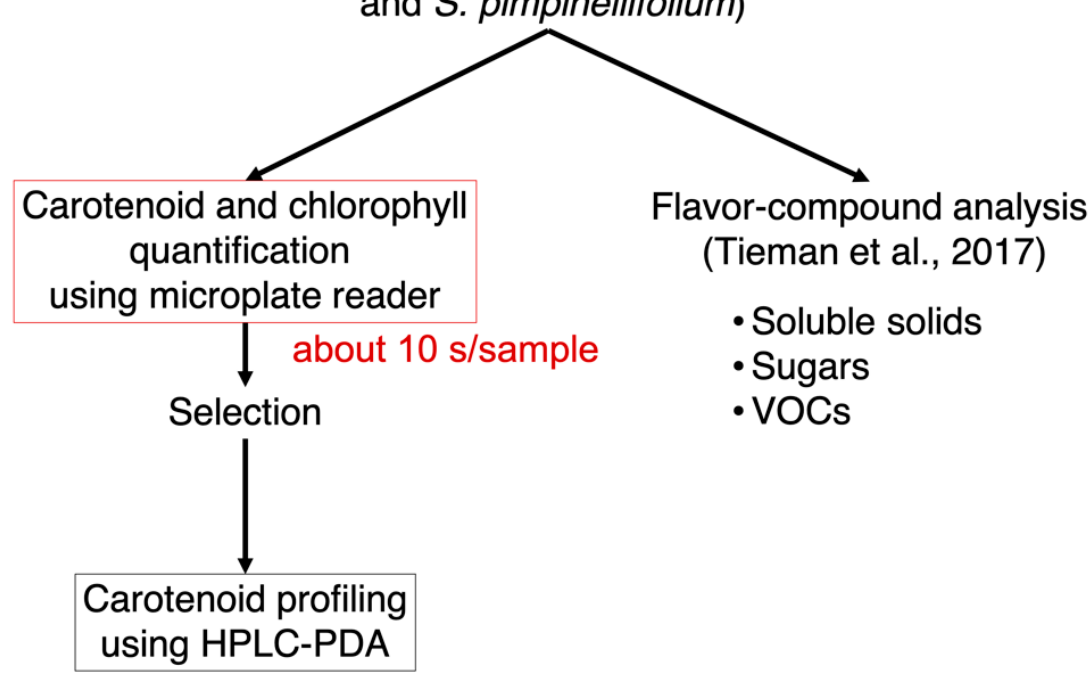

Figure 1. Workflow to quantify nonpolar pigments and flavor-related compounds in tomato fruits. The pigments (carotenoids, lycopene, and chlorophylls a and b) were first quantified by using a multimode microplate reader. After comparison of the pigment composition, several lines were chosen to conduct HPLC-PDA analysis for the quantification of three carotenoids, as well as chlorophylls. Data for flavor-related compounds such as soluble solids, sugars, and VOCs were obtained from Tieman et al. [21].

AC-VOCs are known to accumulate during ripening [14]. In the case of tomato, the ripening stage is discriminated based on skin color appearance [31]. It is well-known that skin colors in fruits, including tomato, are associated with chlorophyll content during ripening [32]. In most tomato varieties, skin color turns from green to red. The developed method can capture common alternations of pigment content in each stage of tomato fruit ripening in well-studied varieties, i.e., "Ailsa Craig" (AC), "Moneymaker" (MM), and "Micro-Tom" (MT), at the three different ripening stages (Figures 2 and S3). To obtain insights into the accumulation of pigments and flavor-related compounds such as sugars and AC-VOCs, we applied the method to quantify the pigments in 157 varieties of tomato fruits.

\subsection{Pigment-Associated Characterization of 157 Varieties of Tomato Fruit}

Results of the pigment quantification of 157 varieties are shown in Figure 3 and Table S1. The same "Moneymaker" RR fruit was analyzed in each batch as quality control to validate technical errors in analytical replicates (Table S2). Similar to AC, MT, and MM (Figure $2 \mathrm{~d}-\mathrm{f}$ ), lycopene content accounted for over $50 \%$ of total carotenoids in the fruits of 142 of 157 varieties. Conversely, 12 varieties contained $40 \%$ or less lycopene (Table S1). This result suggested that the composition of carotenoids, especially the ratio of lycopene to other carotenoids, is widely conserved in lycopene-accumulating varieties, such as redor brown-fruited varieties, even though the total amount of carotenoids varied. This trend was not observed in yellow- and green-fruited varieties that showed no accumulation of lycopene. 
a

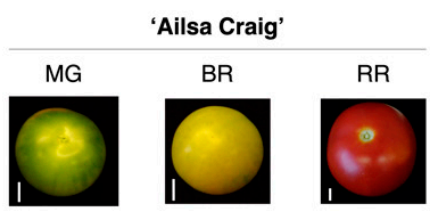

d

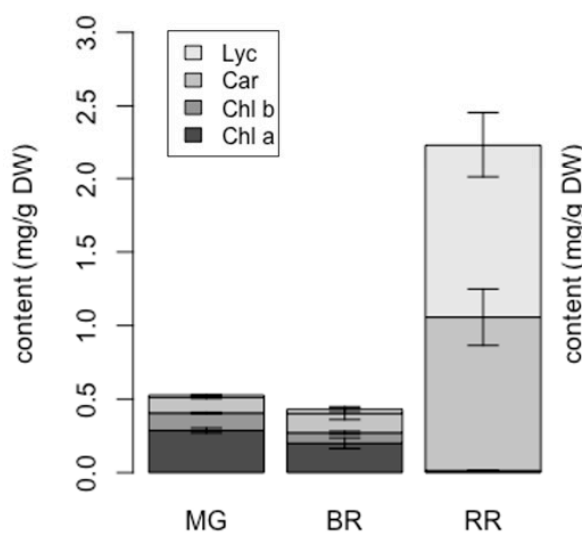

Ripening Stage b

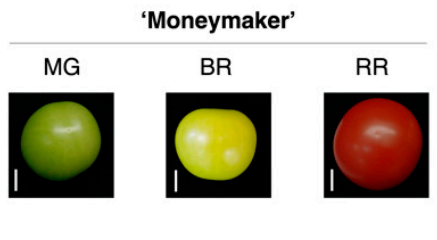

e

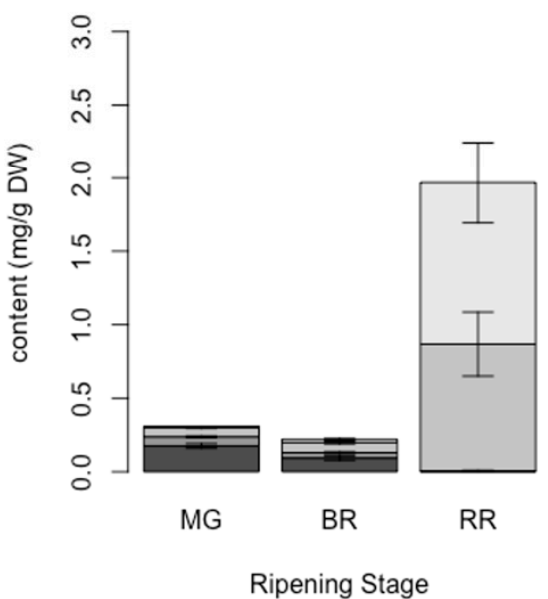

C

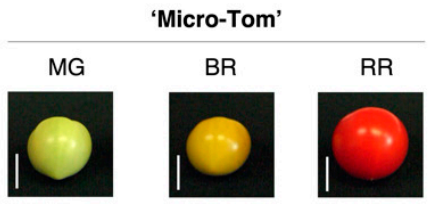

f

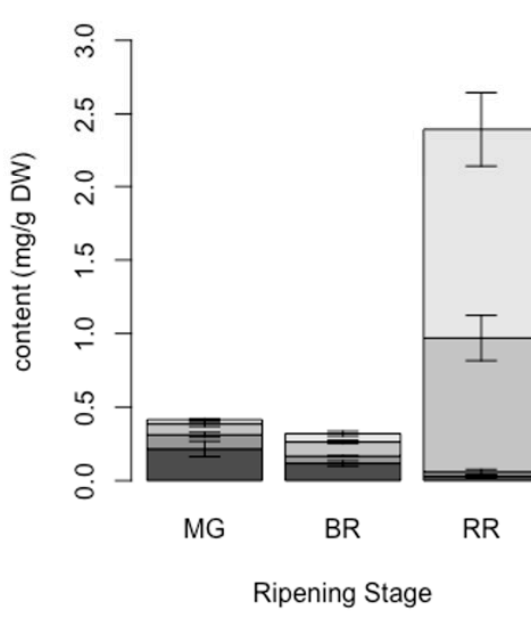

Figure 2. Skin color and pigment content in fruits of three tomato varieties during ripening. (a-c): Appearance and fruit size at different ripening stages of "Ailsa Craig," "Moneymaker," and "Micro-Tom." The white bar indicates $1 \mathrm{~cm}$. (d-f): Quantification of chlorophyll a (Chl a), chlorophyll b (Chl b), total carotenoids except for lycopene (Car), and lycopene (Lyc) content in the three varieties. Each value is shown as the average of biological replicates $(n=3)$ with standard deviation (SD).
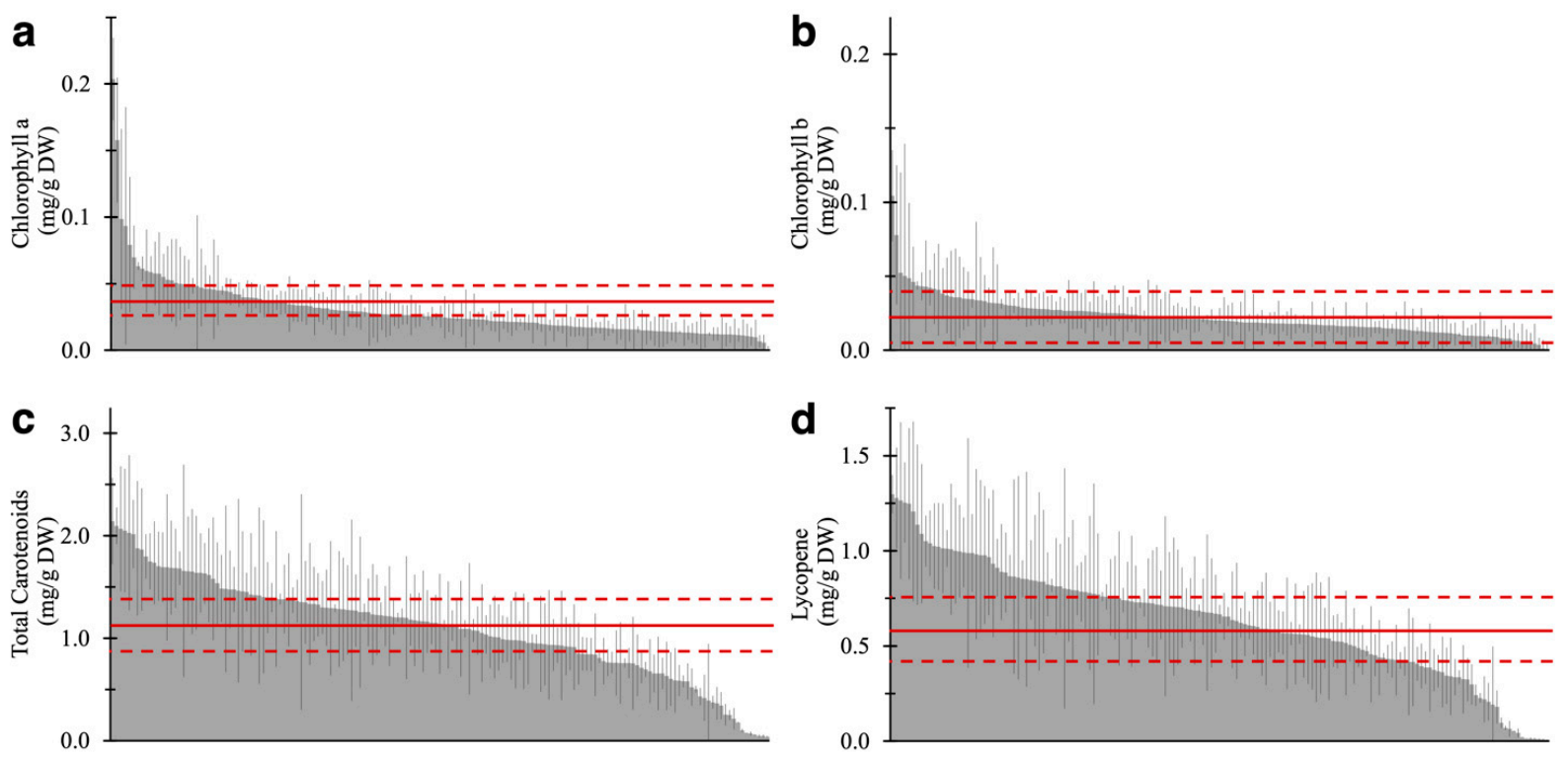

Figure 3. The four-pigment content in ripe fruit of 157 tomato varieties. (a) Chlorophyll a, (b) chlorophyll b, (c) total carotenoids, and (d) lycopene content are shown. The average and SD of the pigment content in AC are represented by the solid and dotted line, respectively. Each value is shown as the average of biological replicates $(n=2-3)$ and analytical replicates $(N=1-2)$ with $\mathrm{SD}$.

\subsection{Association between Pigments and Flavor-Related Compounds}

To elucidate the effect of fruit color-based selection on flavor, we compared quantitative data of the pigments with those of flavor-related compounds from [21], as taste-related compounds, soluble solids, glucose, and fructose content are available for all varieties except for "Bear Creek." Chlorophylls are the primary pigments and vital for photosynthesis, 
while sugars can be synthesized via the Calvin-Benson cycle. To obtain insights between chlorophyll content and sugar accumulation in tomato fruits, we evaluated the association between them (Figures $4 \mathrm{a}, \mathrm{b}$ and S4). The average of soluble solids, glucose, and fructose content in the 16 varieties with the top $10 \%$ chlorophyll a content was significantly higher than that of the bottom $10 \%$. Of the 16 varieties, three varieties were MG-like or BR-like (proportion of chlorophyll content was $>50 \%$ in total pigments with less lycopene), while the other 13 varieties were red-fruited types (lycopene ratio in total carotenoids was about $50 \%$ ). This finding suggested an association between the amount of chlorophylls and the three taste-related metabolites, including sugars.

(a) Glucose

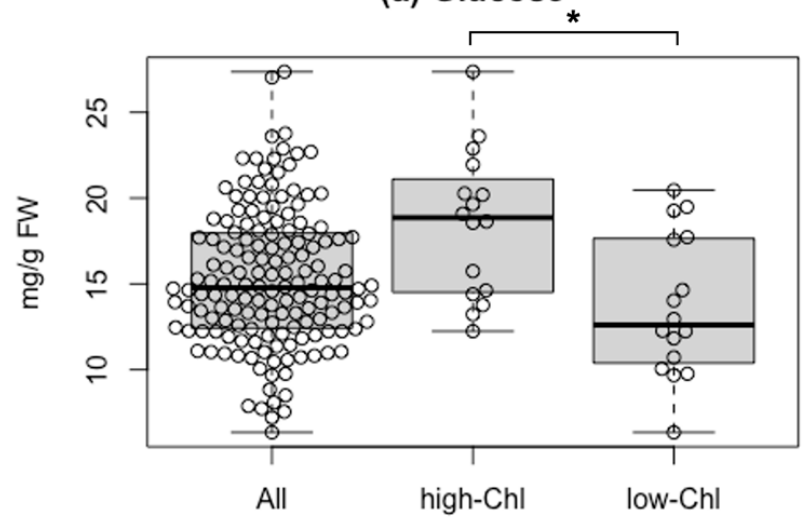

(c) Geranylacetone

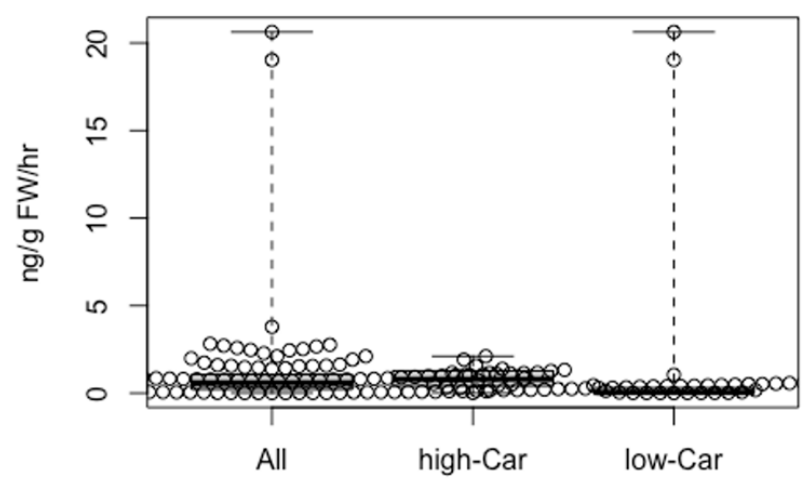

(b) Fructose

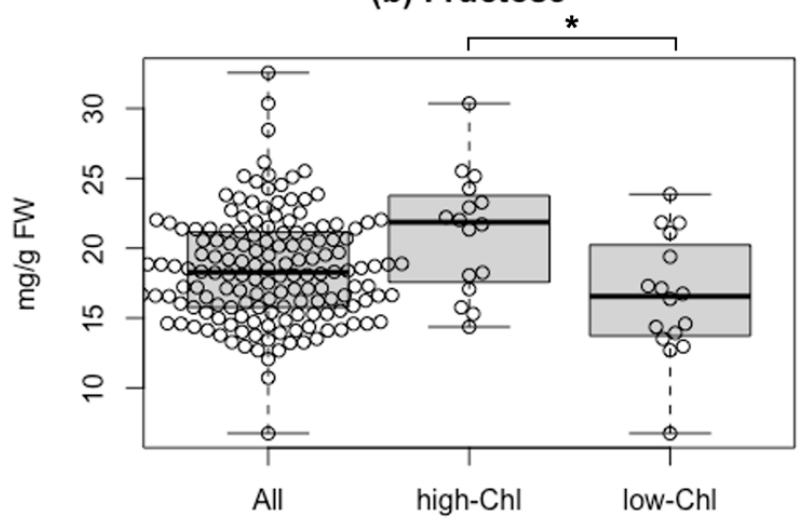

(d) $\mathrm{MHO}$

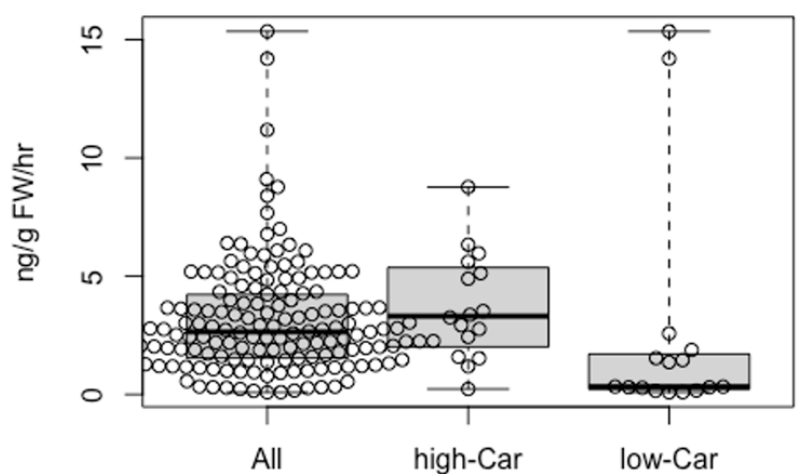

Figure 4. Comparison of flavor-related compounds between varieties with different pigment contents. (a) Glucose and (b) fructose in fruits of the 156 varieties (All), the top 16 varieties with high chlorophyll a content (high-Chl), and the bottom 16 varieties with low chlorophyll a content (low-Chl). Glucose and fructose contents in fruits of the 156 varieties were obtained from data in Tieman et al. [21]. (c) Geranylacetone and (d) MHO in fruits of the 157 varieties (All), the top 16 varieties with high total carotenoid content (high-Car), and the bottom 16 varieties with low total carotenoid content (low-Car). Geranylacetone and 6-methyl-5-hepten-2-one (MHO) contents in fruits of 157 varieties were obtained from Tieman et al. [21]. Asterisks represent a significant difference $\left.{ }^{*} p<0.05\right)$ assayed by Welch's $t$-test. Abbreviation: FW, fresh weight.

As several types of aroma compounds, such as AC-VOCs, can be synthesized by cleavage of carotenoids, we focused on two AC-VOCs, 6-methyl-5-hepten-2-one (MHO) and geranylacetone, in the 157 varieties [21]. In the 16 varieties with the bottom $10 \%$ total carotenoids content, eight varieties contained $1 / 10$ or less of the average content of ACVOCs (Figure 4c,d). Conversely, two varieties showed a very high AC-VOC accumulation despite very low lycopene and total carotenoid content. One is an orange-fruited variety named "Dixie Golden Giant," and the other is a yellow-fruited variety named "Kellogg's Breakfast" (Figure S5). In the two varieties, the MHO content, produced directly by the cleavage of lycopene, was about five times higher than the average. This finding suggested 
that a different carotenoid as a substrate to produce MHO in "Dixie Golden Giant" and "Kellogg's Breakfast" likely exists.

\subsection{Evaluation of Relationships between Fruit Color Variation, Carotenoid Composition, and AC-VOC Content in Eight Representative Varieties}

We conducted HPLC-based carotenoid profiling to compare carotenoid accumulation patterns in eight tomato varieties. One was a red-fruited variety, and the other seven were chosen based on the pigment content and fruit color in the 157 varieties (Table S3). The variety "Ailsa Craig" was used as a representative of a red-fruited tomato, while five varieties were chosen in S. lycopersicum. Two varieties ("Bear Creek" and "Chocolate Cherry") showed a brown color. The variety "Dixie Golden Giant" exhibits an orange color skin and contains very high levels of AC-VOCs in fruits. The varieties "N135 Green Gage" and "Green Zebra" showed a BR-like color (yellow) and a MG-like color (green), respectively. Two S. lycopersicum var. cerasiforme varieties ("Lemon Drop" and "Poire Jaune") showing yellow colors were also chosen. These varieties accumulated very low ACVOC content in their fruits [21]. Chromatograms of these varieties are shown in Figure 5. As expected, lycopene-accumulating varieties, i.e., "Ailsa Craig" and the two varieties with a brown color, showed similar chromatographic patterns (Figure 5i-iii, Table S4). Most of the peaks except for beta-carotene and lutein were missing in chromatograms of the four varieties that contained very low levels of lycopene (Figure 5v-viii, Table S5). In the variety "Dixie Golden Giant," an unknown peak (peak No. 9) was detected, and there was no accumulation of lycopene or other peaks found in the other varieties (Figure 5iv, Table S5). Based on the UV spectrum pattern of the unknown compound and those of the reported carotenoids, the compound was presumed to be prolycopene (Figure S6) [23,25,33]. As the fruit over-accumulates $\mathrm{MHO}$, prolycopene is a potential substrate to produce $\mathrm{MHO}$ instead of trans-lycopene (see Section 3).

IS

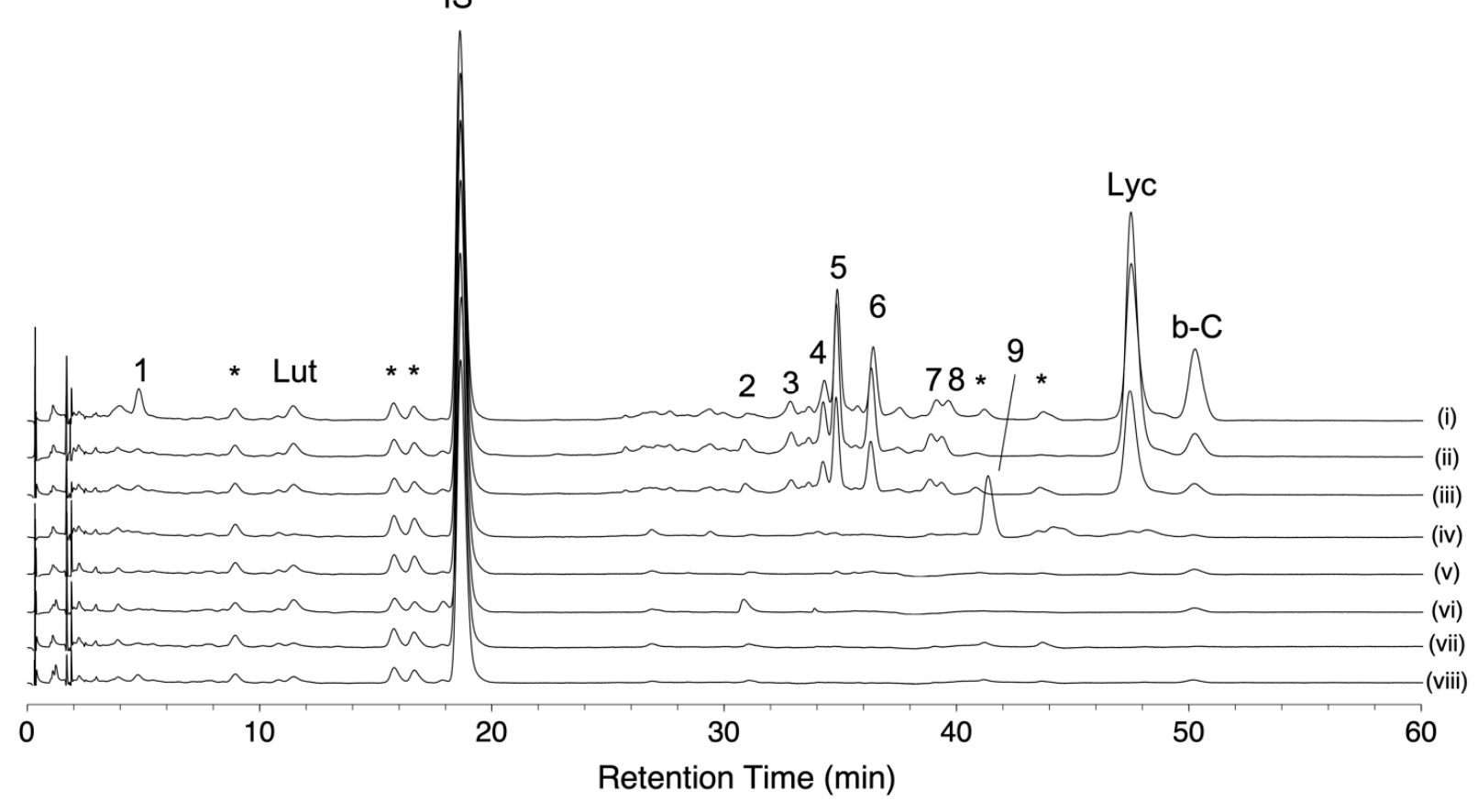

Figure 5. Carotenoid profiles of eight representative varieties analyzed by using HLPC-PDA. Carotenoid profiles were visualized at the wavelength of $450 \mathrm{~nm}$. Each chromatogram shows the pattern of "Ailsa Craig" (i), "Bear Creek" (ii), “Chocolate Cherry" (iii), “Dixie Golden Giant" (iv), "Green Gage” (v), “Green Zebra” (vi), “Lemon Drop" (vii), and "Poire Jaune" (viii). Lycopene (Lyc), beta-carotene (b-C), and lutein (Lut) were identified by comparison to authentic standards. Spectral characteristics of peaks No. 1-9 are shown in Table S5. Peaks with an asterisk are co-eluents that were not carotenoids (see Section 4 in detail). 


\section{Discussion}

To investigate whether the quantity of the major nonpolar pigments in tomato fruits, i.e., carotenoids, lycopene, and chlorophylls, can affect the accumulation of flavor-related compounds, we developed a simple and high-throughput method for the quantification of these pigments. The developed method could capture changes in pigment composition during tomato ripening stages in three well-known varieties. The high-throughput quantification of these pigments in 157 tomato varieties, and the concentration of sugars and AC-VOCs enabled us to select eight varieties representing the range of color in ripe fruits for carotenoid profiling. The result showed that carotenoid profiles reflect the appearance of fruit color and AC-VOC accumulation. Among the tested varieties, the orange-fruited variety showed over-accumulation of prolycopene and MHO.

We integrated data of chlorophylls and taste-related compounds in the 157 tomato fruits. Our results showed that high sugar content was found in varieties with high chlorophyll accumulation (Figure 4a,b). This result suggests a link between chlorophylls and high sugar content. A candidate gene involving a regulatory link between chlorophylls and sugar production is SlGLK2 [33,34]. This gene encodes a transcription factor affecting chloroplast development and localization. A functional allele causes a phenotype called "green shoulder," showing a dark-green region on the stem end in green fruit found in many wild species. As it causes uneven ripening and often remains orange, green, or white in ripe fruit, the loss-of-function allele called " $\mathrm{u}$ " has been selected by breeders in almost all modern commercial cultivars. However, it is believed that the selection of this phenotype caused a reduction in sugar content in modern varieties. Thus far, this theory is based on analysis using near-isogenic wild type and $u$ mutants. Our results demonstrate that chlorophylls in fruit positively correlate with sugar content in the actual variety population.

Our results indicate that lycopene content accounts for about half of the total carotenoids in fruit in approximately $90 \%(142 / 157)$ of the tomato varieties (Table S1). In red tomato fruits, lycopene and its derivatives such as beta-carotene, lutein, and zeaxanthin are the main carotenoids present [35]. Our results suggest that the ratio of lycopene to these other carotenoids is widely preserved among varieties. One possible explanation is that carotenoid biosynthesis in tomato fruit can be tightly regulated by the expression balance between PSY1 (a gene encoding a key enzyme in carotenoid synthesis) and genes involved in the downstream pathway of carotenoid biosynthesis [31,35]. Previous studies indicated that enhancement of the carotenoid pathway by over-expression of PSY1 caused the feed-forward up-regulation of $C Y C$ - $B$ transcription, a fruit-specific lycopene cyclase and lycopene cyclization activity [36]. In addition, over 30 regulatory elements are present in the promoter region of PSY1 [37], potentially diversifying the regulation of expression. In summary, the total amount of carotenoids in tomato fruits can vary depending on PSY1 expression, but the ratio of lycopene among the varieties may remain constant by controlling downstream pathways. It is known that carotenoid content in tomato fruit is largely influenced by changes in growth conditions (e.g., light, temperature, season, drought stress, salinity stress, and pedoclimatic conditions) [9,38-41]. Analyzing associations between carotenoid and $\mathrm{AC}-\mathrm{VOC}$ content in tomato fruits grown under different growth conditions may reveal further clues for improving AC-VOC production.

When integrating carotenoid and aroma-related profiles, the variety 'Dixie Golden Giant' displayed an abnormal accumulation of prolycopene and MHO content. As these AC-VOCs can be generated by cleavage of the linear end of carotenoids [42], they can be derived from the all-trans form (all-trans-lycopene) or from the cis form (prolycopene). A recent study demonstrated that this variety exhibits a mutation in the gene coding for carotene isomerase (CRTISO), an enzyme involved in the isomerization of prolycopene (tetra-cis-lycopene) to all-trans-lycopene [43]. Generally, most lycopene in tomato fruit exists as the all-trans form and crystallizes in the tomato chromoplast [44]. Recent studies have shown that cis-carotenoids exhibit lower crystallinity and higher solubility than the all-trans form $[45,46]$. Researchers have shown that the loss of CRTISO function caused the over-accumulation of prolycopene instead of lycopene and its derivatives in fruit [47]. 
Additionally, mutants with a loss of CRTISO function display several times higher MHO and geranylacetone than their predecessors [20,48]. Similar to "Dixie Golden Giant," "Kellogg's Breakfast" also showed the highest MHO content (Figure 4). A previous study showed that the fruit color of the variety was yellow and the variety accumulated high prolycopene [49]. Given the over-accumulation of prolycopene in both varieties, its likely fate is to be efficiently converted to $\mathrm{MHO}$ and to contribute to the increase in tomato fruits.

In this study, we developed a high-throughput quantification method for nonpolar pigment profiling using a multimode microplate reader. Integrating data of pigment profiles, sugars, and AC-VOCs showed that (i) chlorophylls in fruit correlate with high sugar accumulation, and (ii) one of the yellow fruit varieties with high AC-VOC content, "Dixie Golden Giant," accumulates prolycopene as a putative substrate.

In conclusion, our results suggest that carotenoids and chlorophylls in tomato can influence flavor traits, such as sugar content and aroma composition. The quantitative methods using a microplate reader can be a powerful tool to screen large-scale populations, such as mutant collections and natural accessions, not only for tomato but also for other fruits and vegetables accumulating these pigments.

\section{Materials and Methods}

\subsection{Chemicals}

All chemicals except for the standard of chlorophyll b, trans- $\beta$-apo- $8^{\prime}$-Carotenal, and lutein were purchased from Fujifilm Wako Pure Chemical (Osaka, Japan). Standards of chlorophyll b and trans- $\beta$-apo- $8^{\prime}$-carotenal were purchased from Sigma-Aldrich (Tokyo, Japan). Lutein standard was purchased from EXTRASYNTHESE S.A. (Genay, France).

\subsection{Plant Materials and Sample Collection}

Three varieties of tomato (S. lycopersicum) were grown, and the fruits were harvested at the University of Tsukuba. "Micro-Tom" plants were grown in a greenhouse under natural sunlight supplemented with additional light (16:30-22:00). Hyponex (Hyponex Japan Corp., Ltd., Osaka, Japan) diluted with water was applied to plants once a week as a nutrient. "Ailsa Craig" and "Moneymaker" plants were also grown in a greenhouse under natural sunlight. Hyponex (Hyponex Japan Corp., Ltd., Osaka, Japan) diluted with water was applied to plants once a week as a nutrient. Fruits of each variety were harvested at three different stages: (i) Mature Green (MG), (i) Breaker (BR), and (iii) Red Ripe (RR). The ripening stage of each fruit was estimated based on "USDA Visual Aid TM-L-1" (USDA Agri-cultural Marketing Service, 1975). Skin color of all harvested fruits was measured using a colorimeter (CM-700d, Konica Minolta, Tokyo, Japan). The average of three different points at the equatorial part of the fruit was calculated to represent the color of each fruit. For carotenoid measurement, fruits were lyophilized at least $48 \mathrm{~h}$ after chopping and removing seed and locular gel. After that, dried fruits were crushed and stored at $-80^{\circ} \mathrm{C}$ until analysis. In addition, 157 varieties of cultivated and wild tomatoes, including S. lycopersicum, S. l. var. cerasiforme, and S. pimpinellifolium, were cultivated and harvested at the University of Florida for screening. Harvested whole fruits were homogenized and lyophilized for at least $48 \mathrm{~h}$ and then stored at $-80^{\circ} \mathrm{C}$ until analysis.

\subsection{Extraction and High-Throughput Measurement for Quantification of the Targeted Pigments Using Microplate Reader}

Lyophilized fruits stored at $-80^{\circ} \mathrm{C}$ were acclimated to room temperature for $1 \mathrm{~h}$. Two milligrams of lyophilized fruits were homogenized with $0.4 \mathrm{~mL}$ of acetone by TissueLyser II (Qiagen, Hilden, Germany) for $10 \mathrm{~min}$ at $15 \mathrm{~Hz}$. After centrifugation $(15,000 \mathrm{rpm}$, $5 \mathrm{~min}, 20^{\circ} \mathrm{C}$ ), the supernatant was collected and placed on ice. The same process was repeated twice, resulting in the collection of about $0.7 \mathrm{~mL}$ of extracts. For the absorbance measurement, a microplate reader (Infinite M200Pro, Tecan, Männedorf, Switzerland) was used. Three hundred microliters of the extracts were applied to a custom 96-well glass microplate (Nikkei Products CO., LTD, Osaka, Japan). The optical density was measured 
at $663,647,470,506$, and $750 \mathrm{~nm}(\leq \pm 1.5 \mathrm{~nm})$. The following formula was used to correct the optical path length and calculate each wavelength:

$$
A x=\left(O D x-O D_{750}\right) / l
$$

(Ax: absorbance at $x \mathrm{~nm} ; O D x$ : measured optical density at $x \mathrm{~nm} ; l$ : path length of microplate $(=0.876887 \mathrm{~cm}))$.

\subsection{Calculation of Carotenoid and Chlorophyll Content}

Using the formula created with reference to previous reports [27-29], chlorophyll a, chlorophyll b, total carotenoids, and lycopene content were calculated.

$$
\begin{aligned}
& \text { Chl a (mg/g DW): } C a=\left(11.24 A_{662}-2.04 A_{645}\right) \times(v / w) \\
& \text { Chl b (mg/g DW): } \mathrm{Cb}=\left(20.13 A_{645}-4.19 A_{662}\right) \times(v / w)
\end{aligned}
$$

Total Carotenoids $(\mathrm{mg} / \mathrm{g} \mathrm{DW})=\left\{\left(1000 A_{470}-1.90 \mathrm{Ca}-63.14 \mathrm{Cb}\right) / 214\right\} \times(v / w)$

$$
\text { Lycopene }(\mathrm{mg} / \mathrm{g} \mathrm{DW})=\left(A_{506} / 315\right) \times(v / w)
$$

$A_{\mathrm{x}}$ : absorbance at $x \mathrm{~nm} ; v$ : volume of solvent $(\mathrm{mL}) ; w$ : weight of sample (mg)

\subsection{Pigment Extraction and Carotenoid Profiling Using HPLC}

For carotenoid extraction and HPLC analysis, we utilized a modification of Kimbara et al. [50]. After removal from storage, lyophilized fruit were acclimated to room temperature for $1 \mathrm{~h}$. Seven milligrams of lyophilized fruit was extracted with $1155 \mu \mathrm{L}$ of chloroform/methanol $(1: 1, v / v)$ containing $12 \mu \mathrm{M}$ of trans- $\beta$-apo- $8^{\prime}$-carotenal. The samples were homogenized by TissueLyser II (Qiagen, Hilden, Germany) for 5 min at $8 \mathrm{~Hz}$. After adding $196 \mu \mathrm{L}$ of water, the sample was centrifuged at $13,000 \times g$ for $10 \mathrm{~min}$ at room temperature. One thousand microliters of the supernatant was collected, and $240 \mu \mathrm{L}$ of water was added. After keeping the sample on ice for $2 \mathrm{~h}$ and following centrifugation $\left(1000 \times g\right.$ for $10 \mathrm{~min}$ at $\left.4{ }^{\circ} \mathrm{C}\right), 340 \mu \mathrm{L}$ of the organic phase was collected. These extracts were concentrated by drying with SPD2010 SpeedVac ${ }^{\circledR}$ (Thermo Fisher Scientific, Waltham, MA, USA) and resolving with $81 \mu \mathrm{L}$ of chloroform/ethanol $(1: 1, v / v)$. Then, they were shaken for $5 \mathrm{~min}$ and sonicated for $2 \mathrm{~min}$. After centrifugation $\left(17,800 \times g\right.$ for $15 \mathrm{~min}$ at $\left.4^{\circ} \mathrm{C}\right), 60 \mu \mathrm{L}$ of supernatant was used for HPLC analysis.

An HPLC system (Shimadzu, Kyoto, Japan) was used in this analysis. One microliter of extract was injected into a Develosil C30-UG-5 2.0/250 (Nomura Chemical Co. Ltd., Seto, Japan) at a flow rate of $0.37 \mathrm{~mL} / \mathrm{min}$. The column oven was set to $30^{\circ} \mathrm{C}$. Eluent $\mathrm{A}$, methanol containing $4.5 \%$ water and $0.1 \%$ triethylamine; and eluent $\mathrm{B}$, hexane/isopropyl alcohol (60:40, $v / v$. 0.1\% triethylamine), were used as the mobile phase. The gradient program was as shown in Table S6. To detect analytes, a photodiode array detector (SPDM20AD, Shimadzu, Kyoto, Japan) was used in the wavelength range between 200 and $800 \mathrm{~nm}$. Chromatograms at $450 \mathrm{~nm}$ (for carotenoids) and $650 \mathrm{~nm}$ (for chlorophylls) were used to calculate the peak height. Peak identification and quantification were conducted using LabSolutions Ver. 5.89 (Shimadzu, Kyoto, Japan). Peaks were identified by their retention time and absorption spectra comparison to those of standards (chlorophyll a and $\mathrm{b}$, beta-carotene, lutein, and lycopene) or estimated to be a carotenoid based on exhibiting absorption maxima at 400-500 $\mathrm{nm}$ [27].

\subsection{Statistical Analysis}

All quantitative values were calculated using Excel (Microsoft Office 2019). Welch's $t$-test was performed by $\mathrm{R} 4.0 .2$. Values of $p<0.05$ were considered significantly different.

Supplementary Materials: The following are available online at https:/ / www.mdpi.com/article/10 .3390 / metabo11060398/s1, Figure S1: Calibration curve of dilution series, Figure S2: Plots of HPLC vs. microplate reader quantification results, Figure S3: Color changes in fruits during ripening, 
Figure S4: Comparison of soluble solids content in high and low chlorophyll varieties, Figure S5: Comparison of amount of the four pigments in fruits of "Dixie Golden Giant," "Kellogg's Breakfast," and "Ailsa Craig.", Figure S6: UV spectra of peak No.9 and all-trans-lycopene, Table S1: The pigment content in fruits of the 157 varieties, Table S2: Technical error validation of the pigment profiling using microplate reader applied with the developed method, Table S3: Characteristics of the eight representative varieties used in the study, Table S4: Content of identified carotenoids in the eight tomato varieties using HPLC analysis, Table S5: Relative content and characteristics of unidentified carotenoids in selected tomato lines, Table S6: Gradient time program of HPLC analysis used in the study.

Author Contributions: Conceptualization, Y.A. (Yusuke Aono), H.K. and M.K.; methodology, Y.A. (Yonathan Asikin) and M.K.; formal analysis, Y.A. (Yusuke Aono); validation, Y.A. (Yusuke Aono), Y.A. (Yonathan Asikin), D.T. and M.K.; investigation, Y.A. (Yusuke Aono); resources, N.W. and D.T.; data curation, Y.A. (Yusuke Aono) and M.K.; writing-original draft preparation, Y.A. (Yusuke Aono); writing-review and editing, M.K.; visualization, Y.A. (Yusuke Aono); supervision, M.K. and H.K.; project administration, M.K.; funding acquisition, H.K. and M.K. All authors have read and agreed to the published version of the manuscript.

Funding: This research was funded by the "Sustainable Food Security Research Project" in the form of an operational grant from the National University Corporation and The Yanmar Environmental Sustainability Support Association, Japan. This work was also supported partly by JSPS KAKENHI (Grant Number 19K05711 to M.K). Work by H.K. and D.T. was supported by a grant from the National Science Foundation (IOS 1855585).

Institutional Review Board Statement: Not applicable.

Informed Consent Statement: Not applicable.

Data Availability Statement: The data presented in this study are available in article and supplementary material.

Acknowledgments: We thank Yuka Mitani and Koji Takano for helpful advice about HPLC analysis (RIKEN CSRS, Japan). We thank Kyoko Tanase (University of Tsukuba, Japan), Ken Hoshikawa (Japan International Research Center for Agricultural Sciences, Japan), and Yoshihito Shinozaki (Tokyo University of Agriculture and Technology, Japan) for providing plant materials of "Ailsa Craig" and "Moneymaker". Plant materials of "Ailsa Craig" and "Moneymaker" were provided by Tsukuba-Plant Innovation Research Center (T-PIRC), University of Tsukuba, through the National BioResource Project (NBRP), MEXT, Japan.

Conflicts of Interest: The authors declare no conflict of interest.

\section{References}

1. Martina, M.; Tikunov, Y.; Portis, E.; Bovy, A.G. The Genetic Basis of Tomato Aroma. Genes 2021, 12, 226. [CrossRef]

2. Small, D.M.; Prescott, J. Odor/taste integration and the perception of flavor. Exp. Brain Res. 2005, 166, 345-357. [CrossRef]

3. Baldwin, E.A.; Goodner, K.; Plotto, A. Interaction of volatiles, sugars, and acids on perception of tomato aroma and flavor descriptors. J. Food Sci. 2008, 73, S294-S307. [CrossRef] [PubMed]

4. Zhu, G.; Gou, J.; Klee, H.; Huang, S. Next-Gen Approaches to Flavor-Related Metabolism. Annu. Rev. Plant Biol. 2019, 70, 187-205. [CrossRef] [PubMed]

5. Alonge, M.; Wang, X.; Benoit, M.; Soyk, S.; Pereira, L.; Zhang, L.; Suresh, H.; Ramakrishnan, S.; Maumus, F.; Ciren, D.; et al. Major Impacts of Widespread Structural Variation on Gene Expression and Crop Improvement in Tomato. Cell 2020, 182, 1-17. [CrossRef]

6. Gao, L.; Gonda, I.; Sun, H.; Ma, Q.; Bao, K.; Tieman, D.M.; Burzynski-chang, E.A.; Fish, T.L.; Stromberg, K.A.; Sacks, G.L.; et al. The tomato pan-genome uncovers new genes and a rare allele regulating fruit flavor. Nat. Genet. 2019, 51, 1044-1051. [CrossRef]

7. Bai, Y.; Lindhout, P. Domestication and Breeding of Tomatoes: What have We Gained and What Can We Gain in the Future? Ann. Bot. 2007, 100, 1085-1094. [CrossRef] [PubMed]

8. Coyago-cruz, E.; Corell, M.; Moriana, A.; Mapelli-brahm, P.; Hernanz, D.; Stinco, C.M.; Beltrán-sinchiguano, E.; Meléndezmartínez, A.J. Study of commercial quality parameters, sugars, phenolics, carotenoids and plastids in different tomato varieties. Food Chem. 2019, 277, 480-489. [CrossRef]

9. Quinet, M.; Angosto, T.; Yuste-Lisbona, F.J.; Blanchard-Gros, R.; Bigot, S.; Martinez, J.P.; Lutts, S. Tomato Fruit Development and Metabolism. Front. Plant Sci. 2019, 10, 1-23. [CrossRef]

10. Giovannoni, J.J. Genetic regulation of fruit development and ripening. Plant Cell 2004, 16, 170-180. [CrossRef] [PubMed] 
11. Carrari, F.; Asis, R.; Fernie, A.R. The metabolic shifts underlying tomato fruit development. Plant Biotechnol. 2007, $24,45-55$. [CrossRef]

12. Tieman, D.M.; Zeigler, M.; Schmelz, E.A.; Taylor, M.G.; Bliss, P.; Kirst, M.; Klee, H.J. Identification of loci affecting flavour volatile emissions in tomato fruits. J. Exp. Bot. 2006, 57, 887-896. [CrossRef] [PubMed]

13. Ortiz-Serrano, P.; Gil, J.V. Quantitative comparison of free and bound volatiles of two commercial tomato cultivars (Solanum lycopersicum L.) during ripening. J. Agric. Food Chem. 2010, 58, 1106-1114. [CrossRef] [PubMed]

14. Rambla, J.L.; Tikunov, Y.M.; Monforte, A.J.; Bovy, A.G.; Granell, A. The expanded tomato fruit volatile landscape. J. Exp. Bot. 2014, 65, 4613-4623. [CrossRef] [PubMed]

15. Dono, G.; Rambla, J.L.; Frusciante, S.; Granell, A.; Diretto, G.; Mazzucato, A. Color Mutations Alter the Biochemical Composition in the San Marzano Tomato Fruit. Metabolites 2020, 10, 110. [CrossRef]

16. Hetherington, S.E.; Smillie, R.M.; Davies, W.J. Photosynthetic activities of vegetative and fruiting tissues of tomato. J. Exp. Bot. 1998, 49, 1173-1181. [CrossRef]

17. Cocaliadis, M.F.; Fernández-muñoz, R.; Pons, C.; Orzaez, D.; Granell, A. Increasing tomato fruit quality by enhancing fruit chloroplast function. A double-edged sword ? J. Exp. Bot. 2014, 65, 4589-4598. [CrossRef]

18. Britton, G. Structure and properties of carotenoids in relation to function. FASEB J. 1995, 9, 1551-1558. [CrossRef]

19. Klee, H.J. Improving the flavor of fresh fruits: Genomics, biochemistry, and biotechnology. New Phytol. 2010, 187, 44-56. [CrossRef]

20. Vogel, J.T.; Tieman, D.M.; Sims, C.A.; Odabasi, A.Z.; Clark, D.G.; Klee, H.J. Carotenoid content impacts flavor acceptability in tomato (Solanum lycopersicum). J. Sci. Food Agric. 2010, 90, 2233-2240. [CrossRef]

21. Tieman, D.; Zhu, G.; Resende, M.F.R.; Lin, T.; Nguyen, C.; Bies, D.; Rambla, J.L.; Beltran, K.S.O.; Taylor, M.; Zhang, B.; et al. A chemical genetic roadmap to improved tomato flavor. Science 2017, 355, 391-394. [CrossRef] [PubMed]

22. Rothan, C.; Diouf, I.; Causse, M. Trait discovery and editing in tomato. Plant J. 2019, 97, 73-90. [CrossRef] [PubMed]

23. Yoo, H.J.; Park, W.J.; Lee, G.M.; Oh, C.S.; Yeam, I.; Won, D.C.; Kim, C.K.; Lee, J.M. Inferring the genetic determinants of fruit colors in tomato by carotenoid profiling. Molecules 2017, 22, 764. [CrossRef]

24. Sérino, S.; Gomez, L.; Costagliola, G.; Gautier, H. HPLC assay of tomato carotenoids: Validation of a rapid microextraction technique. J. Agric. Food Chem. 2009, 57, 8753-8760. [CrossRef]

25. Fraser, P.D.; Pinto, M.E.S.; Holloway, D.E.; Bramley, P.M. Application of high-performance liquid chromatography with photodiode array detection to the metabolic profiling of plant isoprenoids. Plant J. 2000, 24, 551-558. [CrossRef] [PubMed]

26. Gupta, P.; Sreelakshmi, Y.; Sharma, R. A rapid and sensitive method for determination of carotenoids in plant tissues by high performance liquid chromatography. Plant Methods 2015, 11, 5. [CrossRef] [PubMed]

27. Lichtenthaler, H.K.; Buschmann, C. Chlorophylls and carotenoids: Measurement and characterization by UV-VIS spectroscopy. Curr. Protoc. Food Anal. Chem. 2001, 1, F4.3.1-F4.3.8. [CrossRef]

28. Nagata, M.; Yamashita, I. Simple Method for Simultaneous Determination of Chlorophyll and Carotenoids in Tomato Fruit. J. Jpn. Soc. Food Sci. Technol. 1992, 39, 925-928. [CrossRef]

29. Ito, H.; Horie, H. Proper Solvent Selection for Lycopene Extraction in Tomatoes and Application to a Rapid Determination. Bull. Natl. Inst. Veg. Tea Sci. 2009, 8, 165-173.

30. Matsumoto, H.; Ikoma, Y.; Kato, M.; Kuniga, T.; Nakajima, N.; Yoshida, T. Quantification of carotenoids in citrus fruit by LC-MS and comparison of patterns of seasonal changes for carotenoids among citrus varieties. J. Agric. Food Chem. 2007, 55, 2356-2368. [CrossRef]

31. Shinozaki, Y.; Nicolas, P.; Fernandez-Pozo, N.; Ma, Q.; Evanich, D.J.; Shi, Y.; Xu, Y.; Zheng, Y.; Snyder, S.I.; Martin, L.B.B.; et al. High-resolution spatiotemporal transcriptome mapping of tomato fruit development and ripening. Nat. Commun. 2018, 9, 364. [CrossRef]

32. Pesaresi, P.; Mizzotti, C.; Colombo, M.; Masiero, S. Genetic regulation and structural changes during tomato fruit development and ripening. Front. Plant Sci. 2014, 5, 124. [CrossRef] [PubMed]

33. Isaacson, T.; Ronen, G.; Zamir, D.; Hirschberg, J. Cloning of tangerine from tomato reveals a carotenoid isomerase essential for the production of $\beta$-carotene and xanthophylls in plants. Plant Cell 2002, 14, 333-342. [CrossRef] [PubMed]

34. Powell, A.L.T.; Nguyen, G.V.; Hill, T.; Cheng, K.L.; Figueroa-Balderas, R.; Aktas, H.; Ashrafi, H.; Pons, C.; Fernandes-Munoz, R.; Vicente, A.; et al. Uniform ripening Encodes a Golden 2-like Transcription Factor Regulating Tomato Fruit Chloroplast Development. Science. 2012, 336, 1711-1715. [CrossRef] [PubMed]

35. Nguyen, C.V.; Vrebalov, J.T.; Gapper, N.E.; Zheng, Y.; Zhong, S.; Fei, Z.; Giovannoni, J.J. Tomato GOLDEN2-LIKE Transcription Factors Reveal Molecular Gradients That Function during Fruit Development and Ripening. Plant Cell 2014, $26,585-601$. [CrossRef] [PubMed]

36. Liu, L.; Shao, Z.; Zhang, M.; Wang, Q. Regulation of carotenoid metabolism in tomato. Mol. Plant 2015, 8, 28-39. [CrossRef]

37. Fraser, P.D.; Enfissi, E.M.A.; Halket, J.M.; Truesdale, M.R.; Yu, D.; Gerrish, C.; Bramley, P.M. Manipulation of Phytoene Levels in Tomato Fruit: Effects on Isoprenoids, Plastids, and Intermediary Metabolism. Plant Cell 2007, 19, 3194-3211. [CrossRef]

38. Efremov, G.I.; Slugina, M.A.; Shchennikova, A.V.; Kochieva, E.Z. Differential regulation of phytoene synthase psy1 during fruit carotenogenesis in cultivated and wild tomato species (Solanum section lycopersicon). Plants 2020, 9, 1169. [CrossRef]

39. Dumas, Y.; Dadomo, M.; Di Lucca, G.; Grolier, P. Effects of environmental factors and agricultural techniques on antioxidant content of tomatoes. J. Sci. Food Agric. 2003, 83, 369-382. [CrossRef] 
40. Borghesi, E.; González-Miret, M.L.; Escudero-Gilete, M.L.; Malorgio, F.; Heredia, F.J.; Meléndez-Martínez, A.J. Effects of salinity stress on carotenoids, anthocyanins, and color of diverse tomato genotypes. J. Agric. Food Chem. 2011, 59, 11676-11682. [CrossRef]

41. Raffo, A.; La Malfa, G.; Fogliano, V.; Maiani, G.; Quaglia, G. Seasonal variations in antioxidant components of cherry tomatoes (Lycopersicon esculentum cv. Naomi F1). J. Food Compos. Anal. 2006, 19, 11-19. [CrossRef]

42. Mallamace, D.; Corsaro, C.; Salvo, A.; Cicero, N.; Macaluso, A.; Giangrosso, G.; Ferrantelli, V.; Dugo, G. A multivariate statistical analysis coming from the NMR metabolic profile of cherry tomatoes (The Sicilian Pachino case). Phys. A Stat. Mech. Its Appl. 2014, 401, 112-117. [CrossRef]

43. Vogel, J.T.; Tan, B.; Mccarty, D.R.; Klee, H.J. The Carotenoid Cleavage Dioxygenase 1 Enzyme Has Broad Substrate Specificity, Cleaving Multiple Carotenoids at Two Different Bond Positions. J. Biol. Chem. 2008, 283, 11364-11373. [CrossRef] [PubMed]

44. Roohanitaziani, R.; de Maagd, R.A.; Lammers, M.; Molthoff, J.; Meijer-Dekens, F.; van Kaauwen, M.P.W.; Finkers, R.; Tikunov, Y.; Visser, R.G.F.; Bovy, A.G. Exploration of a resequenced tomato core collection for phenotypic and genotypic variation in plant growth and fruit quality traits. Genes 2020, 11, 1278. [CrossRef]

45. Simkin, A.J.; Gaffé, J.; Alcaraz, J.P.; Carde, J.P.; Bramley, P.M.; Fraser, P.D.; Kuntz, M. Fibrillin influence on plastid ultrastructure and pigment content in tomato fruit. Phytochemistry 2007, 68, 1545-1556. [CrossRef]

46. Alagoz, Y.; Nayak, P.; Dhami, N.; Cazzonelli, C.I. Cis-carotene biosynthesis, evolution and regulation in plants: The emergence of novel signaling metabolites. Arch. Biochem. Biophys. 2018, 654, 172-184. [CrossRef]

47. Honda, M.; Kodama, T.; Kageyama, H.; Hibino, T.; Kanda, H.; Goto, M. Enhanced Solubility and Reduced Crystallinity of Carotenoids, $\beta$-Carotene and Astaxanthin, by Z-Isomerization. Eur. J. Lipid Sci. Technol. 2018, 120, 1800191. [CrossRef]

48. Lewinsohn, E.; Sitrit, Y.; Bar, E.; Azulay, Y.; Meir, A.; Zamir, D.; Tadmor, Y. Carotenoid Pigmentation Affects the Volatile Composition of Tomato and Watermelon Fruits, As Revealed by Comparative Genetic Analyses. J. Agric. Food Chem. 2005, 53, 3142-3148. [CrossRef]

49. Pek, Z.; Helyes, L.; Gyulai, G.; Foshee, W.; Daood, H.; Lau, J.; Waters, L. Molecular Profiling-Fruit Carotenoids Components of Six American Heirloom Tomatoes (Solanum lycopersicum). J. Forensic Biomech. 2016, 7. [CrossRef]

50. Kimbara, J.; Yoshida, M.; Ito, H.; Kitagawa, M.; Takada, W.; Hayashi, K.; Shibutani, Y.; Kusano, M.; Okazaki, Y.; Nakabayashi, R.; et al. Inhibition of cutin deficient 2 causes defects in cuticle function and structure and metabolite changes in tomato fruit. Plant Cell Physiol. 2013, 54, 1535-1548. [CrossRef] 